Article

\title{
Synthesis and Characterization of Cry2Ab-AVM Bioconjugate: Enhanced Affinity to Binding Proteins and Insecticidal Activity
}

\author{
Zhi-Zhen Pan ${ }^{1,2}$, Lian Xu ${ }^{3}$, Yi-Shu Zheng ${ }^{3}$, Li-Yang Niu ${ }^{3}$, Bo Liu ${ }^{2}$, Nan-Yan Fu ${ }^{4}$, Yan Shi ${ }^{3}$, \\ Qing-Xi Chen ${ }^{3}\left(\mathbb{D}\right.$, Yu-Jing Zhu ${ }^{2, *}$ and Xiong Guan ${ }^{1, *} \mathbb{D}$ \\ 1 State Key Laboratory of Ecological Control of Fujian-Taiwan Crop Pests, Key Laboratory of Biopesticide and \\ Chemical Biology of Ministry of Education, College of Plant Protection, Fujian Agriculture and Forestry \\ University, Fuzhou 350002, China \\ 2 Agricultural Bio-Resources Research Institute, Fujian Academy of Agricultural Sciences, \\ Fuzhou 350003, China \\ 3 School of Life Sciences, Xiamen University, Xiamen 361005, China \\ 4 MOE Key Laboratory for Analytical Science of Food Safety and Biology \& Fujian Provincial Key Laboratory \\ of Analysis and Detection Technology for Food Safety, College of Chemistry, Fuzhou University, \\ Fuzhou 350116, China \\ * Correspondence: zyjingfz@163.com (Y.-J.Z.); guanxfafu@126.com (X.G.); \\ Tel./Fax: +86-591-83789259 (Y.-J.Z. \& X.G.)
}

Received: 24 July 2019; Accepted: 15 August 2019; Published: 27 August 2019

\begin{abstract}
Bacillus thuringiensis insecticidal proteins (Bt toxins) have been widely used in crops for agricultural pest management and to reduce the use of chemical insecticides. Here, we have engineered $\mathrm{Bt}$ toxin $\mathrm{Cry} 2 \mathrm{Ab} 30$ and bioconjugated it with 4"-O-succinyl avermectin (AVM) to synthesize $\mathrm{Cry} 2 \mathrm{Ab}-\mathrm{AVM}$ bioconjugate. It was found that $\mathrm{Cry} 2 \mathrm{Ab}-\mathrm{AVM}$ showed higher insecticidal activity against Plutella xylostella, up to 154.4 times compared to Cry2Ab30. The binding results showed that $\mathrm{Cry} 2 \mathrm{Ab}-\mathrm{AVM}$ binds to the cadherin-like binding protein fragments, the 10th and 11th cadherin repeat domains in the P. xylostella cadherin $\left(\mathrm{PxCR}_{10-11}\right)$, with a much higher affinity (dissociation equilibrium constant $\left.K_{D}=3.44 \mathrm{nM}\right)$ than Cry2Ab30 $\left(K_{D}=28.7 \mathrm{nM}\right)$. Molecular docking suggested that the macrolide lactone group of Cry2Ab-AVM ligand docking into the $\mathrm{PxCR}_{10-11}$ is a potential mechanism to enhance the binding affinity of Cry2Ab-AVM to $P \mathrm{CR}_{10-11}$. These findings offer scope for the engineering of $\mathrm{Bt}$ toxins by bioconjugation for improved pest management.
\end{abstract}

Keywords: Cry2Ab-AVM bioconjugate; binding affinity; molecular docking

Key Contribution: The study develops an engineered Cry2Ab by bioconjugation with 4"-O-succinyl avermectin to enhance insecticidal potency against $P$. xylostella. This engineering also improves its affinity to the cadherin-like binding fragments. Homology modeling and docking study are also carried out to investigate the binding model.

\section{Introduction}

Bacillus thuringiensis insecticidal proteins (Bt toxins) have been shown to be highly effective in agricultural pest control [1,2]. Bt toxins are widely expressed in crops for agricultural pest management and reduce the use of chemical insecticides [3]. Bt toxins are considered as environmentally friendly biological pesticides as they can kill insect pests with little harm to most other organisms and cause few side effects to the ecosystem $[4,5]$.

The interaction of $\mathrm{Bt}$ toxins with binding proteins on the surface of insect midgut cells can lead to oligomerization, membrane insertion, pore formation, and insect death [6-10]. The downregulation 
or deletion of these binding proteins may weaken or disrupt the interaction with Bt toxins, which would result in inefficient insect control or cause insect resistance [1,11-13]. Engineering of Bt toxin to enhance its affinity to binding proteins in insects can improve Bt toxin potency, expand Bt toxin specificity, and bypass receptor-related resistance mechanisms [14-17]. For example, Badram et al. developed a phage-assisted continuous evolution selection that created a rapidly evolving Bt toxin Cry1Ac which binds a cadherin-like receptor from the insect pest Trichoplusia ni that is not natively bound by wild-type Cry1Ac, with a high affinity to improve the insecticidal potency and overcome insect $\mathrm{Bt}$ toxin resistance [15].

In this study, we used bioconjugation to evolve the Bt toxin to enhance its insecticidal activity and improve affinity to its binding proteins. 1-Ethyl-3-(3-dimethylaminopropyl) carbodiimide (EDC) and $\mathrm{N}$-hydroxysuccinimide (NHS) were selected as the couplers, which are carboxyl and amine-reactive zero-length crosslinkers [18]. EDC/NHS reacted with the carboxylic group of the bioconjugation ligand first, and formed an NHS ester intermediate that reacted with an amino group of Bt toxin to form a stable amide bond [19]. Cry2Ab30 was chosen as the target Bt toxin to be modified, which is a $65 \mathrm{kDa}$ 3D-Cry of Bt toxin [20]. Cadherin, formed by a number of characteristic cadherin repeats (CR) domains, a membrane-proximal extracellular domain (MPED), a transmembrane domain, and a cytoplasm domain, serves as an important binding protein for several classes of Cry toxins [21]. For example, Spodoptera exigua cadherin was reported can bind both Cry1Ac and Cry2Aa [22]. Here, the 10th and 11th CR domains (1258-1602 aa) in the Plutella xylostella cadherin (PxCR $10-11$ ) were expressed and chosen as the Cry2Ab-binding protein [23]. Avermectin (AVM) belongs to a family of compounds called the macrocyclic lactones (MLs), and was introduced to the market in the 1980s as an antiparasitic drug and agricultural pesticide [24]. The mode of action of MLs is based on their interaction with the receptor channels for inhibitory neurotransmitters. However, MLs also irreversibly bind to other receptors with high affinity in a process involving macrocyclic groups, such as glutamate and glycine receptors $[25,26]$. Therefore, AVM was selected as the bioconjugation ligand with regarding to its structure-activity, with the aim of improving the affinity of Cry2Ab30 to its binding proteins. Here, AVM was first carbonylated to synthesize 4"-O-succinyl avermectin to improve its bioconjugation activity. Cry2Ab-AVM was then synthesized by bioconjugating 4"-O-succinyl avermectin onto Cry2Ab30 via EDC/NHS, which enhanced the insecticidal activity against $P$. xylostella up to 154.4-fold over Cry2Ab30 and led to binding of PxCR $10-11$ with a higher affinity. These results established an approach to the evolution of Bt toxins and provided a new platform for the engineering of other protein-binding biomolecules.

\section{Results}

\subsection{Preparation and Characterization of $C r y 2 A b-A V M$}

To improve the insecticidal activity of Cry2Ab30, Cry2Ab-AVM was synthesized by bioconjugating 4"-O-succinyl avermectin onto Cry2Ab30 via EDC/NHS. In our previous study, we bioconjugated AVM onto $\mathrm{Bt} \delta$-endotoxin to form GSCS-BtA biocide, which had higher efficacy in reducing the abundance of some important crucifer pests while exhibiting low impact on their natural enemies [27]. Here, we made a modification on AVM to firstly improve its bioconjugation reactivity. AVM contains three hydroxyl groups, with the secondary allylic hydroxyl group at the 5 position is the most reactive, followed by the secondary hydroxyl group at the 4 " position. The tertiary allylic hydroxyl group at the 7 position is too sterically hindered to be reactive [28]. The two reactive hydroxyl groups (5-OH and 4 "'-OH) have the potential to be modified by conjugation with Cry2Ab30. Considering that the $5-\mathrm{OH}$ is located on the macrolide lactone group of AVM, which may interact with the binding proteins of Cry2Ab30, we selected the 4"-OH to be modified by conjugation with Cry2Ab30. 4"-O-succinyl avermectin was synthesized to create a carboxylic group on 4 " position of AVM. The carboxylic group was then converted to NHS ester intermediate in the presence of EDC and NHS, followed by its reaction with amino groups on Cry2Ab30, thus forming a stable amide linkage (Figure 1). Excess EDC, NHS, 4"-O-succinyl avermectin, and NHS esters were removed using a PD-10 desalting column. 


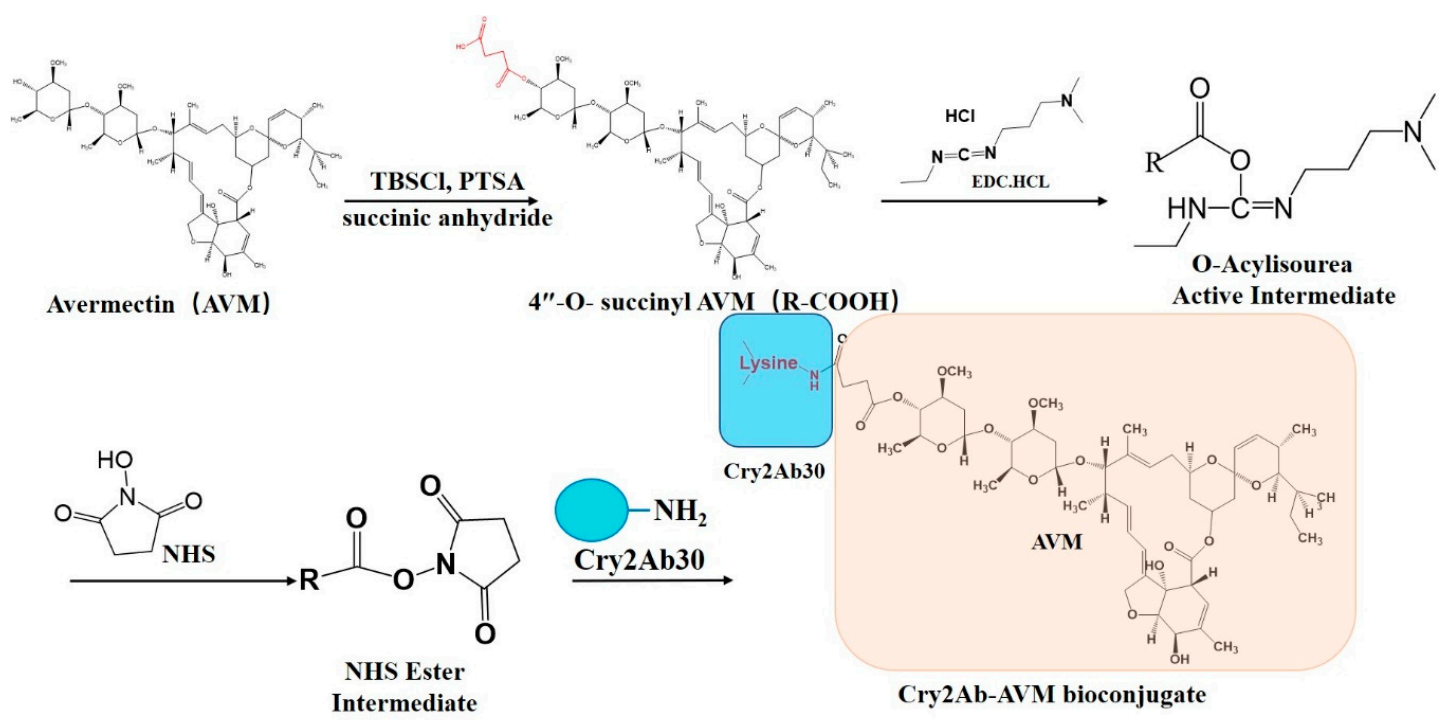

Figure 1. Schematic illustration of the procedures for bioconjugation of Cry2Ab-AVM.

Cry2Ab30 and Cry2Ab-AVM were detected by 10\% SDS-PAGE with Coomassie brilliant blue staining (Figure 2a). Cry2Ab-AVM showed an obvious shift in molecular weight compared with Cry2Ab30 (65 kDa), which demonstrated that 4"-O-succinyl avermectin had been conjugated onto Cry2Ab30. Both Cry2Ab30 and Cry2Ab-AVM were detected by anti-Cry2Ab antibody (Figure 2b) and the results suggested that they were free of any major disturbances to the structure of Cry2Ab30 due to the bioconjugation of 4"-O-succinyl avermectin. We also ran size-exclusion chromatography to detect whether 4"-O-succinyl avermectin was conjugated onto the Cry2Ab30. As shown in Figure 2c,d, the elution time of $\mathrm{Cry} 2 \mathrm{Ab}-\mathrm{AVM}$ was earlier than $\mathrm{Cry} 2 \mathrm{Ab}$, suggesting that the bioconjugation of 4 "-O-succinyl avermectin onto Cry2Ab30 increased the molecular weight of Cry2Ab30.

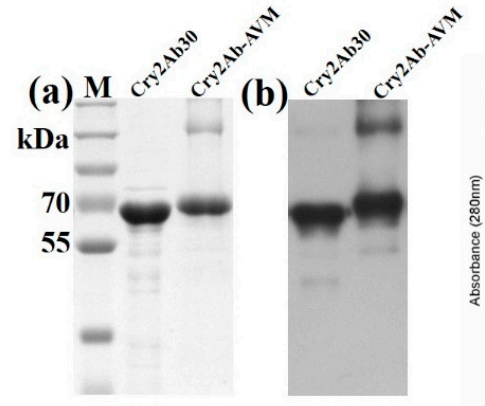

(e)

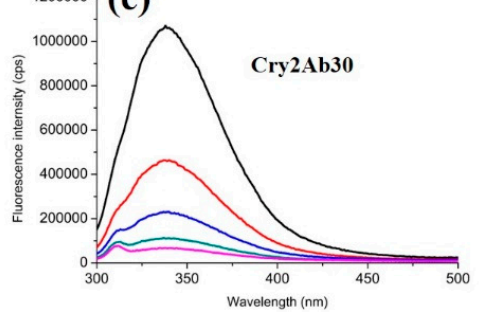

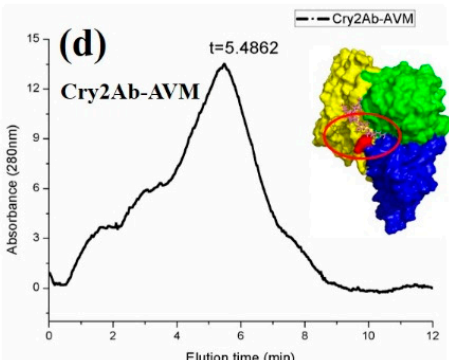

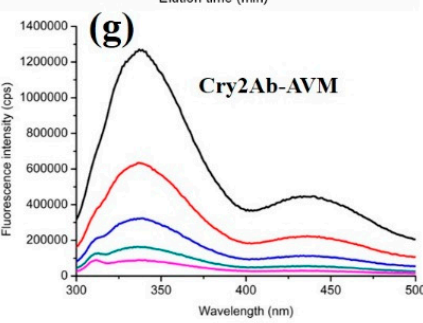

Figure 2. Characterization of Cry2Ab-AVM. Cry2Ab30 and Cry2Ab-AVM were evaluated by $10 \%$ SDS-PAGE (a) and Western blotting using an anti-Cry2Ab antibody (b). Gel filtration elution profiles of Cry2Ab (c) and Cry2Ab-AVM (d) on a Superdex 75 10/30 GL column: the homology modeling of Cry2Ab was shown at the top right corner of (c), the red area indicated the Lys 232 of Cry2Ab30 which was its potential bioconjugate site with 4 "-O-succinyl avermectin; the schematic diagram of $\mathrm{Cry} 2 \mathrm{Ab}-\mathrm{AVM}$ was shown at the top right corner of (d), the red ring region showed 4"-O-succinyl avermectin was covalently conjugated onto Cry2Ab30. Fluorescence emission spectra of Cry2Ab30 (e), $\operatorname{AVM}(\mathbf{f})$, and Cry2Ab-AVM (e) using serial concentrations and $280 \mathrm{~nm}$ excitation. 
The fluorescence emission spectrum of Cry2Ab30 showed a main peak at $330 \mathrm{~nm}$ (Figure 2e). The fluorescence emission spectrum of AVM showed two peaks at 330 and $430 \mathrm{~nm}$ (Figure 2f). The main emission peak of AVM at $430 \mathrm{~nm}$ was also unique and distinguished it from Cry2Ab30. After coupling of 4"-O-succinyl avermectin onto Cry2Ab30, the fluorescence emission spectrum of Cry2Ab-AVM showed two peaks at 330 and $430 \mathrm{~nm}$ (Figure 2g), which suggested that 4"-O-succinyl avermectin was conjugated onto Cry2Ab30. Furthermore, an avermectin enzyme-linked immunosorbent assay using anti-avermectin antibodies could also detect AVM in Cry2Ab-AVM, but not in Cry2Ab30 (Table S1 and Figure S1), demonstrating that 4"-O-succinyl avermectin was conjugated onto Cry2Ab30.

These results suggested that Cry2Ab-AVM was successfully synthesized by bioconjugating $4 "$ "O-succinyl avermectin onto Cry2Ab30.

\subsection{Cry2Ab-AVM Binds to $P x C R_{10-11}$ at Higher Affinity Than Cry2Ab30}

In our previous study, $\mathrm{PxCR}_{10-11}$ is found to be the binding fragment of Cry2Ab30 in P. xylostella cadherin, and may be involved in the action of Cry2Ab30 against P. xylostella [23]. Qiu et al. also reported that the CR7-MPED region in the S. exigua cadherin played an important functional binding site for both Cry1Ac and Cry2Aa, but they did not compete for the same binding site, which suggested that they may bind to diverse cadherin protein epitopes. When cadherin transcription was suppressed by oral RNAi knockdown, the susceptibility of S. exigua larvae to both Cry1Ac and Cry2Aa was significantly reduced. These results suggested that cadherin serves as a specific Cry2A target [22]. Zhao et al. also reported that cadherin may function as receptors for Cry2Aa in Helicoverpa armigera and play important roles in the toxicity of the Cry2Aa toxin [29]. Here, $\mathrm{PxCR}_{10-11}$ was expressed in the Escherichia coli expression system and was further purified using a GST-Sefinose prepacked gravity column (Figure 3a). Ligand blot assay revealed that both Cry2Ab30 and Cry2Ab-AVM could bind $\mathrm{PxCR}_{10-11}$ (Figure $3 \mathrm{~b}$ ). To further assess the kinetic constants of Cry2Ab30 or Cry2Ab-AVM binding to

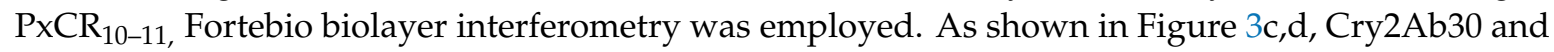
Cry2Ab-AVM both had strong binding affinity to $\mathrm{PxCR}_{10-11}$, characterized by rapid association and slow dissociation. Cry2Ab-AVM showed a significantly higher association rate constant $\left(k_{o n}\right)$ than Cry2Ab30. The $K_{D}$ value for the binding of Cry2Ab30 to PxCR $10-11$ was $28.7 \mathrm{nM}$, which was 8.34-fold larger than that of Cry2Ab-AVM (3.44 nM) (Figure 3e). The results revealed that bioconjugation engineering on Cry2Ab30 could significantly improve its binding affinity to $\mathrm{PxCR}_{10-11}$.

\subsection{Insecticidal Toxicity Bioassay}

We assayed the insecticidal toxicity of Cry2Ab30 or Cry2Ab-AVM against a susceptible laboratory population of P. xylostella. As expected, Cry2Ab-AVM exhibited substantially increased toxicity to P. xylostella larvae compared with Cry2Ab30 (Figure 4a), with median lethal concentration $\left(\mathrm{LC}_{50}\right)$ values up to 154.4-fold lower than Cry2Ab30 (Table 1). The disruption of P. xylostella midgut epithelium fed by Cry2Ab30 or Cry2Ab-AVM was also assayed using transmission electron microscopy (TEM). In the control group, the P. xylostella midgut epithelial cells were intact, and the epithelial microvilli were neatly arranged (Figure $4 \mathrm{~b}$ ). The midgut cross sections showed extensive damage to P. xylostella midgut epithelium and epithelial microvilli that was induced by both Cry2Ab30 and Cry2Ab-AVM (Figure 4c,d). In addition, the degree of damage to the midgut epithelium was apparently greater in the $\mathrm{Cry} 2 \mathrm{Ab}-\mathrm{AVM}$ group relative to the Cry2Ab30 group, which was consistent with the higher toxicity of Cry2Ab-AVM to P. xylostella. 


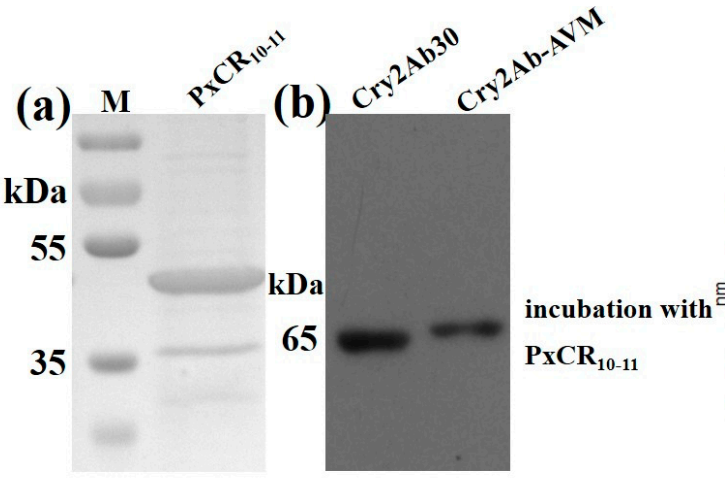

(d) Cry2Ab-AVM binding to $\mathrm{PxCR}_{10-11}$

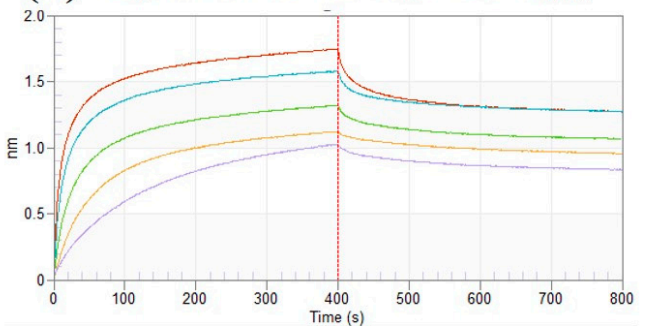

\section{(e)}

\begin{tabular}{|c|c|c|}
\hline Kinetic Constants & Cry2Ab30 & Cry2Ab-AVM \\
\hline $\begin{array}{c}\text { Association rate constant }\left[\mathrm{k}_{\text {on }}\right] \\
\left(\mathrm{M}^{-1} \mathrm{sec}^{-1} / 1 \times 10^{4}\right)\end{array}$ & $1.98 \pm 0.02$ & $16.5 \pm 0.15$ \\
\hline $\begin{array}{c}\text { Dissociation rate constant }\left[k_{\text {off }}\right] \\
\left(\sec ^{-1} / 1 \times 10^{-4}\right)\end{array}$ & $5.67 \pm 0.10$ & $5.69 \pm 0.07$ \\
\hline $\begin{array}{c}\text { Dissociation equilibrium } \\
\text { constant }\left[K_{D}\right](n M) \\
\end{array}$ & $28.7 \pm 0.60$ & $3.44 \pm 0.05$ \\
\hline $\mathbf{R}^{2}$ & 0.9818 & 0.9564 \\
\hline
\end{tabular}

Figure 3. The binding of Cry2Ab30 or Cry2Ab-AVM to PxCR $10-11$. (a) The purity and identity of PxCR $_{10-11}$ was evaluated by $10 \%$ SDS-PAGE. (b) Ligand blot detected the binding abilities of Cry2Ab30 and Cry2Ab-AVM to PxCR $10-11$. Binding kinetics of Cry2Ab30 (c) or Cry2Ab-AVM (d) to PxCR $10-11$ was studied by Fortebio biolayer interferometry, with Cry2Ab30 or Cry2Ab-AVM concentrations ranging from 38.5 to $576.9 \mathrm{nM}$. Kinetics were assessed by fitting data to a 1:1 binding model to determine the rate constants. (e) Summary of kinetic constants. Bioconjugation 4"-O-succinyl avermectin onto Cry2Ab30 could enhance the affinity of Cry2Ab30 to PxCR $10-11$.

Table 1. Bioassay of Cry2Ab30 and Cry2Ab-AVM against Susceptible Laboratory Plutella xylostella Larvae.

\begin{tabular}{cccccc}
\hline Toxin & $\begin{array}{c}\mathbf{L C}_{\mathbf{5 0}} \\
\left(\boldsymbol{\mu g} / \mathbf{c m}^{\mathbf{2}}\right)\end{array}$ & $\begin{array}{c}\mathbf{9 5 \%} \\
\text { Confidence Interval }\end{array}$ & Slope & SE & $\begin{array}{c}\text { Relative } \\
\text { Potency }^{\mathbf{a}}\end{array}$ \\
\hline Cry2Ab30 & 1.544 & $1.041-2.402$ & 1.922 & 0.333 & 1 \\
Cry2Ab-AVM & 0.010 & $0.006-0.016$ & 1.792 & 0.356 & 154.4 \\
\hline
\end{tabular}

${ }^{\mathrm{a}}$ Relative potency is normalized to the insecticidal activity ( $\mathrm{LC}_{50}$ value) of Cry2Ab30.

The insecticidal toxicity and TEM results together revealed that Cry2Ab-AVM showed a higher insecticidal potency than Cry2Ab30. 

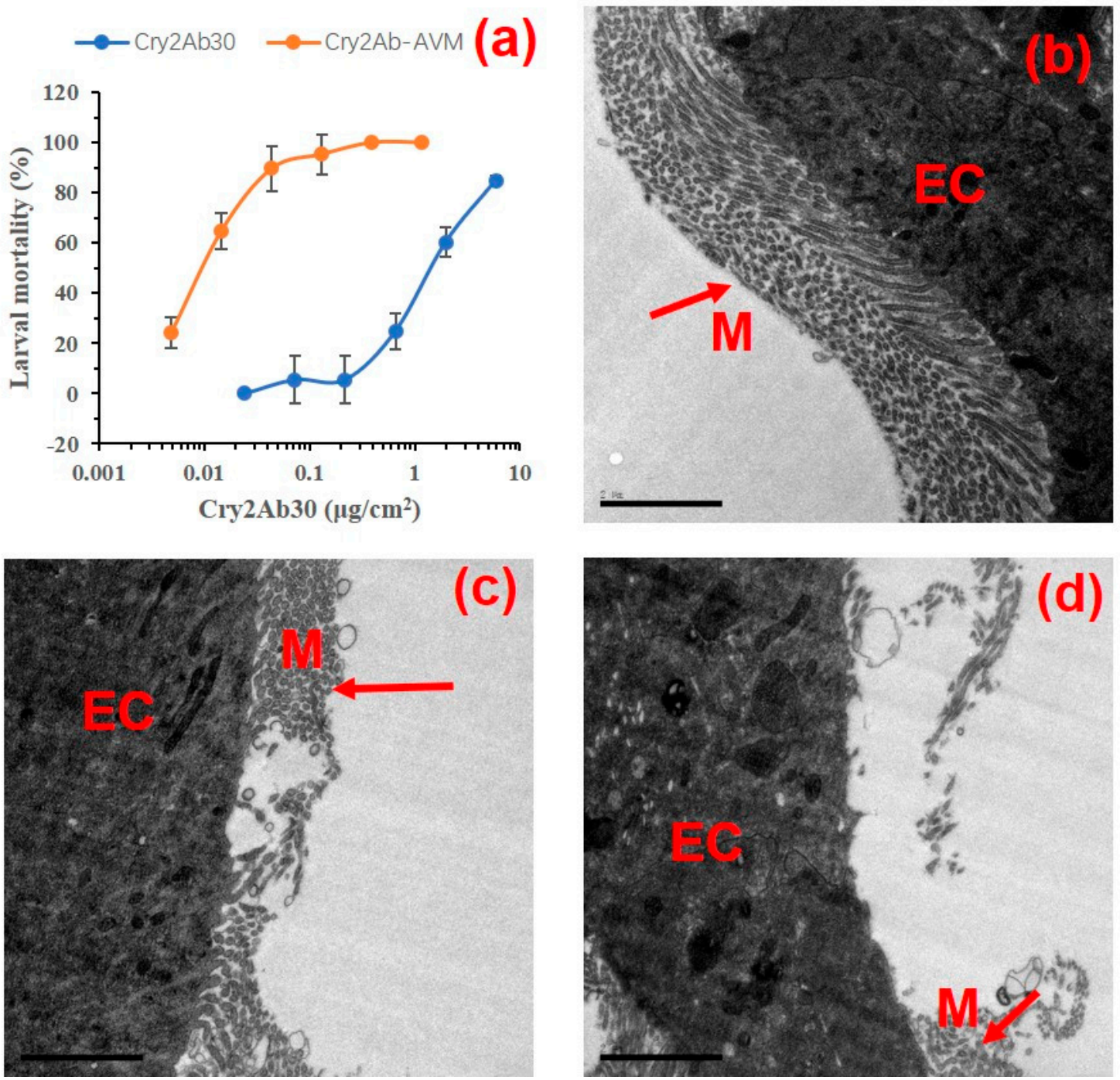

Figure 4. The insecticidal activities of Cry2Ab30 and Cry2Ab-AVM against P. xylostella. (a) The susceptibility of second-instar larvae of P. xylostella to Cry2Ab30 and Cry2Ab-AVM. Data are shown as the mean \pm standard error of the mean $(n=3)$. Ultrastructural (TEM) imaging of general aspects of midgut of P. xylostella (b), the midgut fed with Cry2Ab30 (c), and midgut fed with Cry2Ab-AVM (d). $\mathrm{EC}=$ epithelial cell; $\mathrm{M}=$ microvilli. The scale bar is $2 \mu \mathrm{m}$.

\subsection{Modeling and Docking Analysis}

We further investigated the interaction model of Cry2Ab-AVM ligand (4"-O-succinyl avermectin) with PxCR $10-11$ to explore the potential mechanism by which Cry2Ab-AVM binds to PxCR $\mathrm{R}_{10-11}$ with higher affinity relative to Cry2Ab30 (Figure 5). The homology model of $\mathrm{PxCR}_{10-11}$ was firstly established by I-TASSER servers (Figure 5a). A Ramachandran plot, computed by the PROCHECK program, showed that there were $96.6 \%$ residues located on the allowed region in the $\mathrm{PxCR}_{10-11}$ model, suggesting that the model was reliable. We then predicted the docking sites using the site finder module implemented in Molecular Operating Environment (MOE). The predicted site was found close to the membrane-proximal region of $\mathrm{PxCR}_{11}$, which includes residues Asp 134, Thr 135, Gln 139, Glu 169, Phe 170, Glu 171, and Val 186. 4"-O-succinyl avermectin was then selected as the ligand against this predicted site using the docking module. The results suggested that the active carboxylic group of Cry2Ab-AVM ligand was exposed on the surface of $\mathrm{PxCR}_{11}$, which maybe covalently immobilized on Cry2Ab30. The macrolide lactone group of Cry2Ab-AVM ligand, after Cry2Ab-AVM bound to $\mathrm{PxCR}_{10-11}$, would dock into the activity site of $\mathrm{PxCR}_{11}$ (Figure $5 \mathrm{~b}$ ) and form a hydrogen bond with 
Arg 165 and other interactions with $\mathrm{PxCR}_{11}$ (Figure 5c). This may contribute to the elevated binding affinity of Cry2Ab-AVM with PxCR $_{10-11}$ relative to Cry2Ab30.
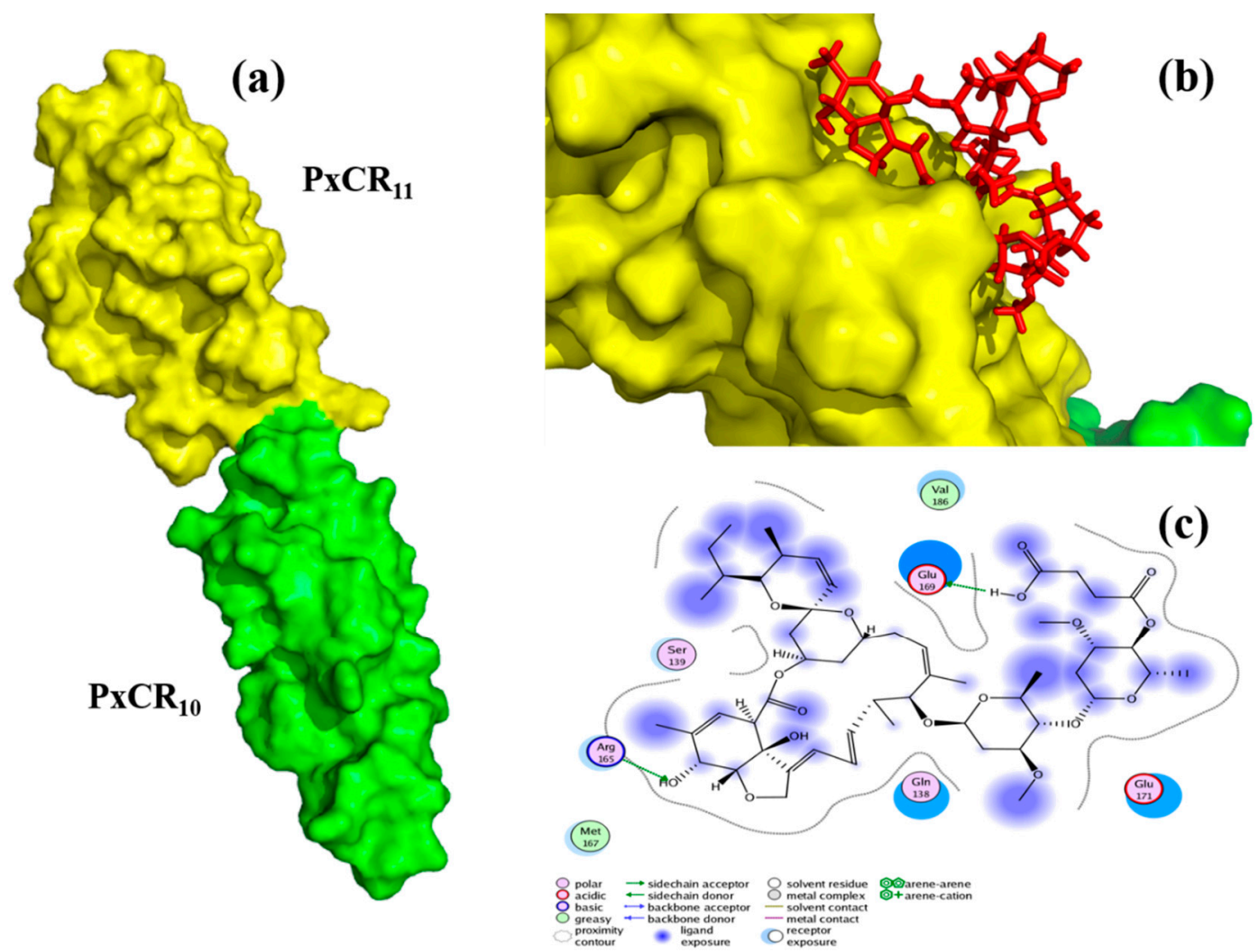

Figure 5. The interaction model of 4"-O-succinyl avermectin with $\mathrm{PxCR}_{10-11}$ by MOE docking study. (a) Surface diagram of PxCR $10-11$ by PyMol, $\mathrm{PxCR}_{10}$ is depicted as a green molecular surface. PxCR 11 (membrane-proximal region) is depicted as a yellow molecular surface. (b) 4"-O-succinyl avermectin docked into the active site of PxCR 11.4 "-O-succinyl avermectin is shown in the stick model in red. (c) Ligand interaction (planar projection of b) showed the possible interactions between 4"-O-succinyl avermectin and $\mathrm{PxCR}_{10-11}$. The solid blue ball of 4"-O-succinyl avermectin represents groups exposed to the PxCR $10-11$ surface.

\section{Discussion}

In this study, we engineered Cry2Ab30 to synthesize a Cry2Ab-AVM bioconjugate and enhanced the insecticidal potency against P. xylostella by up to 154.4-fold compared with Cry2Ab30. We tried to explore the potential mechanism for enhanced insecticidal activity of Cry2Ab-AVM. Protein binding is a crucial step in the insecticidal action of Cry1A [30,31]. It might also be a crucial step for the action for Cry2A as the two have a similar three-dimensional structure [32]. To our best knowledge, although numerous studies have attempted to identify the functional receptor of Cry2A, there no solid conclusions have been reached [33-37]. However, some papers suggested that cadherin is involved in the insecticidal action of Cry2A [22,29]. In our studies, we also found that both Cry2Ab30 and Cry2Ab-AVM could bind PxCR $10-11$. The results of the binding kinetics indicated that Cry2Ab-AVM bound $\mathrm{PxCR}_{10-11}$ at a higher affinity relative to Cry2Ab30, which may be a potential mechanism for the enhanced insecticidal activity of Cry2Ab-AVM. However, further study is required to understand whether this binding affinity is also consistent in the midgut brush border membrane of $P$. xylostella in vivo. In addition, there are other Cry2Ab30 binding proteins, such as PxAPN5 or soluble binding proteins in the midgut juice [38,39]. It is possible that bioconjugation engineering on Cry2Ab30 could also affect the affinity of CryAb30 with these binding proteins, but further study is required to evaluate this. 
Avermectin is a 16-membered macrocyclic lactone derivative, with the macrolide lactone group in its active center [40]. We selected 4"-OH of avermectin to be carbonylated and to be conjugated onto Cry2Ab30, and the macrolide lactone of avermectin would be the functional ligand of Cry2Ab-AVM to interact with the binding proteins of Cry2Ab. The docking analysis suggested that the macrolide lactone group of Cry2Ab-AVM ligand docked into $\mathrm{PxCR}_{10-11}$ to form interaction forces which may enhance the binding affinity of Cry2Ab-AVM to PxCR $10-11$. To further verify the mechanism, 4",5-O-succinyl avermectin was synthesized and conjugated onto Cry2Ab30 to synthesize Cry2Ab-AVMd according to the preparation of Cry2Ab-AVM. 4",5-O-Succinyl avermectin has two carboxylic groups, each in either the 4 " or 5 positions (Figure S2). The 5 position of avermectin was located in the macrolide lactone of avermectin and was more reactive than the 4" position [28]. The carboxylic group in the 5 position would be first conjugated onto Cry2Ab30 via EDC/NHS, which meant that the macrolide lactone of 4",5-O-succinyl avermectin would not interact with $\mathrm{PxCR}_{10-11}$. As expected, the $\mathrm{K}_{\mathrm{D}}$ value for the binding affinity of Cry2Ab-AVMd with $\mathrm{PxCR}_{10-11}$ was only $71.9 \mathrm{nM}$, which was almost the same as Cry2Ab30 (Table S2). In addition, the insecticidal toxicity of Cry2Ab-AVMd against P. xylostella was almost consistent with Cry2Ab30, with a relative potency of 1.06 (Table S3). These results suggested that the bioconjugation of avermectin onto Cry2Ab30 should be carried out in the 4" position of avermectin, which would swing the macrolide lactone group of avermectin to interact with the binding proteins of Cry2Ab30, which may be a key contributor in enhancing the affinity of Cry2Ab-AVM to its binding proteins. The bioconjugation strategy established here offers further scope for the engineering of Bt toxins for improved pest management.

\section{Materials and Methods}

\subsection{Insects}

A laboratory population of P. xylostella was supplied by Bio-Pesticide Engineering Research Center, Wuhan, China [41]. P. xylostella larvae were fed an artificial diet and were maintained under environmental conditions of $27 \pm 2{ }^{\circ} \mathrm{C}, 70 \%$ humidity, and a $14 \mathrm{~h} / 10 \mathrm{~h}(\mathrm{~L} / \mathrm{D})$ photoperiod.

\subsection{Synthesis of 4"-O-Succinyl Avermectin}

4"-O-Succinyl avermectin was synthesized according to previously reported procedures [42,43]. Selective protection of a hydroxyl group at the 5 position of avermectin (Aladdin, Shanghai, China) was carried out by tert-butyldimethylsilyl chloride (TBSCl) (Aladdin, Shanghai, China), and then succinylation of the 4"-hydroxy group was studied using succinic anhydride (Aladdin, Shanghai, China), followed by the deprotection of TBSCl by $p$-toluenesulfonic acid (PTSA) (Aladdin, Shanghai, China), thus synthesizing 4"-O-succinyl avermectin. ${ }^{1} \mathrm{H}$ NMR $\left(400 \mathrm{MHz}, \mathrm{CDCl}_{3}\right) \delta 4.78(\mathrm{~d}, J=3.1 \mathrm{~Hz}$, 1H), $4.68(\mathrm{br}, 2 \mathrm{H}), 3.36(\mathrm{~s}, 3 \mathrm{H}), 2.69(\mathrm{~m}, 4 \mathrm{H}), 1.87(\mathrm{~s}, 3 \mathrm{H}) .{ }^{13} \mathrm{C} \mathrm{NMR}\left(101 \mathrm{MHz}, \mathrm{CDCl}_{3}\right) \delta$ 176.55, 173.73, 171.60, 139.51, 137.99, 137.85, 136.30, 135.17, 127.71, 124.77, 120.42, 118.33, 118.04, 98.33, 95.80, 94.99, $82.02,80.71,80.36,79.23,76.60,75.61,74.91,68.45,68.38,67.68,67.18,66.45,56.93,56.54,45.74,40.45$, $39.73,36.51,35.15,35.00,34.48,34.22,30.57,29.07,28.80,27.49,23.42,20.69,20.23,19.90,18.37,17.32$, 16.37, 15.10, 12.96, 12.04. HRMS (ESI): $995.4969[\mathrm{M}+\mathrm{Na}]^{+}$.

\subsection{Preparation of $\mathrm{Cr} 2 \mathrm{Ab} 30$}

The production and purification of Cry2Ab30 was as described in our previous study [20]. The plasmid of pET30a-cry2Ab30 was transformed into E. coli BL21 (DE3) cells. The bacterial stab was inoculated onto the LB medium containing kanamycin $(35 \mu \mathrm{g} / \mathrm{mL})$ (Aladdin, Shanghai, China) and incubated at $20^{\circ} \mathrm{C}$. The expression of Cry2Ab30 was induced with $0.2 \mathrm{mM}$ isopropyl-B-Dthiogalactopyranoside (IPTG) (Sangon, Shanghai, China) after the $\mathrm{OD}_{600 \mathrm{~nm}}$ reached 0.6. After that, Cry2Ab30 was purified using a Ni-IDA prepacked column (Sangon, Shanghai, China). 


\subsection{Preparation of Truncated Recombinant P. xylostella Cadherin (PxCR $\left.\mathrm{P}_{10-11}\right)$}

The 10th and 11th CR domains (1258-1602 aa) in the P. xylostella cadherin (PxCR $10-11)$ binding Cry2Ab30 were expressed and purified as described in our previous study [23]. Cells were harvested by centrifugation, and the pellets were resuspended in glutathione transferase (GST) binding buffer (140 mM NaCl, $2.7 \mathrm{mM} \mathrm{KCl}, 10 \mathrm{mM} \mathrm{Na}_{2} \mathrm{HPO}_{4}, 1.8 \mathrm{mM} \mathrm{KH}_{2} \mathrm{PO}_{4}, \mathrm{pH}$ 7.4). PxCR $10-11$ was purified using a GST prepacked gravity column (Sangon, Shanghai, China).

\subsection{General Procedure for Cry2Ab-AVM}

$4^{\prime \prime}$-O-Succinyl avermectin $\left(2 \times 10^{-6} \mathrm{~mol}\right)$ was firstly dissolved in $1 \mathrm{~mL}$ of DMF (Macklin, Shanghai, China). Then, triethylamine $\left(2 \times 10^{-5} \mathrm{~mol}\right)$ (Macklin, Shanghai, China) was added to provide protons, EDC $\left(2 \times 10^{-5} \mathrm{~mol}\right)$ (Aladdin, Shanghai, China) was added to form an O-acylisourea active intermediate, and NHS $\left(5 \times 10^{-5} \mathrm{~mol}\right)$ (Aladdin, Shanghai, China) was added to form an NHS ester intermediate; this intermediate was stirred for $0.5 \mathrm{~h}$ at $25^{\circ} \mathrm{C}$ to activate 4 "-O-succinyl avermectin. Cry2Ab30 $\left(2 \times 10^{-8} \mathrm{~mol}\right)$ was desalted into PBS $(0.1 \mathrm{M}, \mathrm{pH} 7.4)$ using a size-exclusion column (GE Healthcare, Piscataway, NJ, USA), and activated 4"-O-succinyl avermectin was then added to Cry2Ab30 PBS buffer. The mixture was vortexed and allowed to react at room temperature for $2 \mathrm{~h}$. After the reaction was completed, Cry2Ab-AVM was purified using a PD-10 desalting column (GE Healthcare, Piscataway, NJ, USA) [44]. Cry2Ab-AVM was detected by SDS-PAGE gel electrophoresis (Bio-Rad, Hercules, CA, USA) and size-exclusion chromatography using a Superdex 75 10/300 GL attached to an AKTA pure 150 (GE Healthcare, Uppsala, Sweden) at a flow rate of $0.8 \mathrm{~mL} / \mathrm{min}$ [45]. The fluorescence spectra of Cry2Ab30 and Cry2Ab-AVM were recorded with a HORIBA Fluoromax-4 spectrofluorometer (HORIBA Scientific, Kyoto, Japan) at excitations of $280 \mathrm{~nm}$ (5 nm bandwidth) and 300-500 nm (5 nm bandwidth) emissions [46]. Furthermore, an avermectin enzyme-linked immunosorbent assay (Randox, Crumlin, UK) using anti-avermectin antibodies was also carried out to detect AVM in Cry2Ab-AVM according to the manual operation.

\subsection{Ligand Blot Assay}

The binding abilities of Cry2Ab30 and Cry2Ab-AVM to PxCR $10-11$ were detected by a ligand blot assay [47]. Cry2Ab30 and Cry2Ab-AVM were separated by 10\% SDS-PAGE and transferred to a polyvinylidene fluoride (PVDF) membrane (Millipore, Darmstadt, Germany). The PVDF membrane was sealed with Tris-buffered saline Tween (TBST) buffer $(20 \mathrm{mM}$ Tris- $\mathrm{HCl}, 150 \mathrm{mM} \mathrm{NaCl}, 0.05 \%$ Tween-20, 0.1\% BSA, pH 7.4) for 60 min with constant shaking. Then, the PVDF membrane was incubated with $10 \mathrm{ng} / \mathrm{mL} \mathrm{PxCR}_{10-11}$ protein in TBST buffer overnight followed by three washes of TBST buffer.

\subsection{Biosensor-Binding Kinetics}

The binding kinetics of Cry2Ab30 or Cry2Ab-AVM to PxCR $10-11$ were assayed on an Octet Red 96 biolayer interferometer (Pall ForteBio Corp., Menlo Park, CA, USA) [48,49]. GST-tagged PxCR $10-11$ was first loaded onto anti-GST biosensors (Pall ForteBio Corp., Menlo Park, CA, USA) for 300 s. The binding of Cry2Ab30 and Cry2Ab-AVM to immobilized PxCR $10-11$ was measured with a $400 \mathrm{~s}$ association followed by a $400 \mathrm{~s}$ dissociation. The buffer was $10 \mathrm{mM} \mathrm{GSH}, 50 \mathrm{mM}$ Tris, pH 8.0. The dissociation equilibrium constant $\left(\mathrm{K}_{\mathrm{D}}\right)$ was determined by Octet System Data Analysis software (Pall ForteBio Corp., Menlo Park, CA, USA) [50-52].

\subsection{Toxicity Assays}

The bioassays of Cry2Ab30 and Cry2Ab-AVM were performed with second-instar P. xylostella. Different doses of Cry2Ab30 and Cry2Ab-AVM solutions were spread on the surface of the diet and allowed to dry. Samples were treated with the same volume of PBS buffer as controls. Thirty individual larvae were used for each concentration. All the bioassay experiments were repeated in triplicates. 
Observations were recorded at $72 \mathrm{~h}$, and the mortality was determined and statistically analyzed using SPSS 17.0 (Statistical Product and Service Solutions, Chicago, IL, USA) [53].

\subsection{Transmission Electron Microscope Analysis}

Third instar larvae of P. xylostella were starved for $5 \mathrm{~h}$ and then fed an artificial diet including Cry2Ab30 or Cry2Ab-AVM for $24 \mathrm{~h}$. Larvae fed with PBS buffer (0.1 M, pH 7.4) were set as negative controls. The larvae were then dissected, and the midgut tissues were then isolated and immediately fixed in $2.5 \%$ glutaraldehyde (Aladdin, Shanghai, China) and post-fixed in $1 \% \mathrm{OsO}_{4}$ (Aladdin, Shanghai, China). The fixed midgut tissues were then immersed into Epon for embedding. Ultrathin sections were sliced using a Leica EM UC7 ultramicrotome (Leica Microsystems, Wetzlar, Germany), and stained with uranyl acetate and then lead citrate [41]. The ultrastructure of midgut epithelium was examined using a transmission electron microscope (JEM-2100HC, JEOL, Tokyo, Japan).

\subsection{Homology Modeling and Docking}

The protein structure of PxCR $10-11$ was built by I-TASSER servers (http://zhanglab.ccmb.med. umich.edu/I-TASSER) and the molecular structure of 4"-O-succinyl avermectin was built using ChemBioDraw Ultra 12.0 (CambridgeSoft, Waltham, MA, USA). Docking of 4"-O-succinyl avermectin to PxCR $10-11$ was analyzed by Molecular Operating Environment (MOE) (Chemical Computing Group Inc., Montreal, QC, Canada) with default parameters; 4"-O-succinyl avermectin was selected as the ligand [54]. All structural images were rendered by PyMol (PyMol molecular graphics system, Schrödinger, LLC.) [55].

Supplementary Materials: The following are available online at http://www.mdpi.com/2072-6651/11/9/497/s1, Supplementary information includes details regarding the ELISA results of Cry2Ab-AVM, synthesis of 4", 5-O-succinyl AVM, and the binding and toxicity assays of Cry2Ab-AVMd. Figure S1: The concentrations of AVM in series dilutions of Cry2Ab30 and Cry2Ab-AVM, Figure S2: The structural formula of 4"-O-succinoyl AVM and 4", 5-O-succinoyl AVM, Table S1: The determination of avermectin (AVM) standards, Table S2: Kinetics of Cry2Ab-AVMd Binding to PxCR $10-11$ in the ForteBio System, Table S3: Bioassay of Cry2Ab30 and Cry2Ab-AVMd against Susceptible Laboratory Plutella xylostella Larvae.

Author Contributions: Conceptualization, Z.-Z.P., Y.-J.Z. and X.G.; Methodology, Z.-Z.P., L.X., Y.-S.Z. and L.-Y.N.; 4"-O-succinoyl avermectin synthesis, Z.-Z.P. and N.-Y.F.; Docking analysis, L.X., Y.S. and Q.-X.C.; insect assay, B.L.; writing-original draft preparation, Z.-Z.P. and L.X.; writing-review and editing, B.L., Q.-X.C., Y.-J.Z. and X.G.; supervision, Y.-J.Z. and X.G.

Funding: The present investigation was supported by the National Natural Science Foundation of China (31701851), the Joint Foundation of Two Sides of Strait (YS2017YFGH000833), the Natural Science Foundation of Fujian Province, China (2016J01130), and the Science Foundation of Fujian Academy of Agricultural Sciences (AB2017-5).

Conflicts of Interest: The authors declare no competing financial interest.

\section{References}

1. PardoLópez, L.; Soberón, M.; Bravo, A. Bacillus thuringiensis insecticidal three-domain Cry toxins: Mode of action, insect resistance and consequences for crop protection. FEMS Microbiol. Rev. 2009, 37, 3-22. [CrossRef]

2. Soberón, M.; Monnerat, R.; Bravo, A. Mode of action of Cry toxins from Bacillus thuringiensis and resistance mechanisms. Microb. Toxins 2016, 1-13. [CrossRef]

3. Lu, Y.; Wu, K.; Jiang, Y.; Guo, Y.; Desneux, N. Widespread adoption of Bt cotton and insecticide decrease promotes biocontrol services. Nature 2012, 487, 362-365. [CrossRef]

4. Kumar, S.; Chandra, A.; Pandey, K.C. Bacillus thuringiensis (Bt) transgenic crop: An environment friendly insect-pest management strategy. J. Environ. Biol. 2008, 29, 641-653.

5. Wu, K.M.; Lu, Y.H.; Feng, H.Q.; Jiang, Y.Y.; Zhao, J.Z. Suppression of cotton bollworm in multiple crops in China in areas with Bt toxin-containing cotton. Science 2008, 321, 1676-1678. [CrossRef]

6. Bravo, A.; Gill, S.S.; Soberon, M. Mode of action of Bacillus thuringiensis Cry and Cyt toxins and their potential for insect control. Toxicon 2007, 49, 423-435. [CrossRef] 
7. Peña-Cardeña, A.; Grande, R.; Sánchez, J.; Tabashnik, B.E.; Bravo, A.; Soberón, M.; Gómez, I. The C-terminal protoxin domain of Bacillus thuringiensis Cry1 Ab toxin has a functional role in binding to GPI-anchored receptors in the insect midgut. J. Biol. Chem. 2018, 293, 20263-20272. [CrossRef]

8. Mushtaq, R.; Shakoori, A.R.; Jurat-Fuentes, J.L. Domain III of Cry1Ac is critical to binding and toxicity against soybean looper (Chrysodeixis includens) but not to velvetbean caterpillar (Anticarsia gemmatalis). Toxins 2018, 10, 95. [CrossRef]

9. Gahan, L.J.; Pauchet, Y.; Vogel, H.; Heckel, D.G. An ABC transporter mutation is correlated with insect resistance to Bacillus thuringiensis Cry1Ac toxin. PLoS Genet. 2010, 6, e1001248. [CrossRef]

10. Rausell, C.; Muñoz-Garay, C.; Miranda-CassoLuengo, R.; Gómez, I.; Rudiño-Piñera, E.; Soberón, M.; Bravo, A. Tryptophan spectroscopy studies and black lipid bilayer analysis indicate that the oligomeric structure of Cry1 Ab toxin from Bacillus thuringiensis is the membrane-insertion intermediate. Biochemistry 2004, 43, 166-174. [CrossRef]

11. Gahan, L.J.; Gould, F.; Heckel, D.G. Identification of a gene associated with Bt resistance in Heliothis virescens. Science 2001, 293, 857-860. [CrossRef]

12. Stevens, T.; Song, S.; Bruning, J.B.; Choo, A.; Baxter, S.W. Expressing a moth ABCC2 gene in transgenic drosophila causes susceptibility to Bt Cry1Ac without requiring a cadherin-like protein receptor. Insect Biochem. Mol. 2017, 80, 61-70. [CrossRef]

13. Flagel, L.; Lee, Y.W.; Wanjugi, H.; Swarup, S.; Brown, A.; Wang, J.L.; Kraft, E.; Greenplate, J.; Simmouns, J.; Adams, N.; et al. Mutational disruption of the ABCC2 gene in fall armyworm, Spodoptera frugiperda, confers resistance to the Cry1Fa and Cry1A. 105 insecticidal proteins. Sci. Rep. 2018, 8, 7255. [CrossRef]

14. Liu, M.M.; Huang, R.; Weisman, A.; Yu, X.Y.; Lee, S.H.; Chen, Y.; Huang, C.; Hu, S.H.; Chen, X.H.; Tan, W.F.; et al. Synthetic polymer affinity ligand for Bacillus thuringiensis (Bt) Cry1Ab/Ac protein. The use of biomimicry based on the Bt protein-insect receptor binding mechanism. J. Am. Chem. Soc. 2018, 140, 6853-6864. [CrossRef]

15. Badran, A.H.; Guzov, V.M.; Huai, Q.; Kemp, M.M.; Vishwanath, P.; Kain, W.; Nance, A.M.; Evdokimov, A.; Moshiri, F.; Turner, K.H.; et al. Continuous evolution of Bacillus thuringiensis toxins overcomes insect resistance. Nature 2016, 533, 58-63. [CrossRef]

16. Gómez, I.; Pardo-López, L.; Munoz-Garay, C.; Fernandez, L.E.; Pérez, C.; Sánchez, J.; Soberon, M.; Bravo, A. Role of receptor interaction in the mode of action of insecticidal Cry and Cyt toxins produced by Bacillus thuringiensis. Peptides 2007, 28, 169-173.

17. Park, Y.; Hua, G.; Taylor, M.D.; Adang, M.J. A coleopteran cadherin fragment synergizes toxicity of Bacillus thuringiensis toxins Cry3Aa, Cry3Bb, and Cry8Ca against lesser mealworm, Alphitobius diaperinus (Coleoptera: Tenebrionidae). J. Invertebr. Pathol. 2014, 123, 1-5. [CrossRef]

18. Jacob, N.T.; Anraku, K.; Kimishima, A.; Zhou, B.; Collins, K.C.; Lockner, J.W.; Ellis, B.A.; Janda, K.D. A bioconjugate leveraging xenoreactive antibodies to alleviate cocaine-induced behavior. Chem. Commun. 2017, 53, 8156-8159. [CrossRef]

19. Qu, Z.; Chen, K.; Gu, H.; Xu, H. Covalent immobilization of proteins on 3D poly (acrylic acid) brushes: Mechanism study and a more effective and controllable process. Bioconj. Chem. 2014, 25, 370-378. [CrossRef]

20. Pan, Z.Z.; Xu, L.; Zhu, Y.J.; Shi, H.; Chen, Z.; Chen, M.C.; Chen, Q.X.; Liu, B. Characterization of a new Cry2Ab gene of Bacillus thuringiensis with high insecticidal activity against Plutella xylostella L. World J. Microb. Biot. 2014, 30, 2655-2662. [CrossRef]

21. ParK, Y.; Kim, Y. RNA interference of cadherin gene expression in Spodoptera exigua reveals its significance as a specific Bt target. J. Invertebr. Pathol. 2013, 114, 285-291. [CrossRef]

22. Qiu, L.; Hou, L.L.; Zhang, B.Y.; Liu, L.; Li, B.; Deng, P.; Ma, W.H.; Wang, X.P.; Fabrick, J.A.; Chen, L.Z.; et al. Cadherin is involved in the action of Bacillus thuringiensis toxins Cry1Ac and Cry2Aa in the beet armyworm, Spodoptera exigua. J. Invertebr. Pathol. 2015, 127, 47-53. [CrossRef]

23. Xu, L.; Liu, B.; Pan, Z.Z.; Zhu, Y.J.; Gao, H.J.; Chen, Q.X. Cloning, prokaryotic expression and functional analysis of PxCR $10-11$ domian in Plutella xylostella cadherin. J. Xianmen Univ. Nat. Sci. 2017, 56, 59-63.

24. Ivermectin and Abamectin; Campbell, W.C. (Ed.) Springer: New York, NY, USA, 1989.

25. Arena, J.; Liu, K.; Paress, P.; Frazier, E.; Cully, D.; Mrozik, H.; Schaeffer, J. The mechanism of action of avermectins in Caenorhabditis elegans: Correlation between activation of glutamate-sensitive chloride current, membrane binding, and biological activity. J. Parasitol. 1995, 81, 286-294. [CrossRef] 
26. Shan, Q.; Haddrill, J.L.; Lynch, J.W. Ivermectin, an unconventional agonist of the glycine receptor chloride channel. J. Biol. Chem. 2001, 276, 12556-12564. [CrossRef]

27. Sengonca, C.; Liu, B. Effect of GCSC-BtA biocide on abundance and diversity of some cabbage pests as well as their natural enemies in southeastern China. J. Plant Dis. Prot. 2003, 110, 484-491. [CrossRef]

28. Tom, L.A.; Foster, N. Development of a molecularly imprinted polymer for the analysis of avermectin. Anal. Chim. Acta 2010, 680, 79-85. [CrossRef]

29. Zhao, M.; Yuan, X.; Wei, J.; Zhang, W.; Wang, B.; Khaing, M.M.; Liang, G. Functional roles of cadherin, aminopeptidase-N and alkaline phosphatase from Helicoverpa armigera (Hübner) in the action mechanism of Bacillus thuringiensis Cry2Aa. Sci. Rep. 2017, 7, 46555. [CrossRef]

30. Soberón, M.; Pardo-López, L.; López, I.; Gómez, I.; Tabashnik, B.E.; Bravo, A. Engineering modified Bt toxins to counter insect resistance. Science 2007, 318, 1640-1642.

31. Melo, A.L.D.A.; Soccol, V.T.; Soccol, C.R. Bacillus thuringiensis: Mechanism of action, resistance, and new applications: A review. Crit. Rev. Biotechnol. 2016, 36, 317-326. [CrossRef]

32. Hernandez-Rodriguez, C.S.; Van Vliet, A.; Bautsoens, N.; Van Rie, J.; Ferre, J. Specific binding of Bacillus thuringiensis Cry2A insecticidal proteins to a common site in the midgut of Helicoverpa species. Appl. Environ. Microb. 2008, 74, 7654-7659. [CrossRef]

33. Guo, Z.; Kang, S.; Zhu, X.; Xia, J.; Wu, Q.; Wang, S.; Xie, W.; Zhang, Y. Down-regulation of a novel ABC transporter gene (Pxwhite) is associated with Cry1Ac resistance in the diamondback moth, Plutella xylostella (L.). Insect Biochem. Mol. 2015, 59, 30-40. [CrossRef]

34. Xu, C.; Wang, B.C.; Yu, Z.; Sun, M. Structural insights into Bacillus thuringiensis Cry, Cyt and parasporin toxins. Toxins 2014, 6, 2732-2770. [CrossRef]

35. Zúñiga-Navarrete, F.; Gómez, I.; Pena, G.; Amaro, I.; Ortíz, E.; Becerril, B.; Ibarra, J.E.; Bravo, A.; Soberón, M. Identification of Bacillus thuringiensis Cry3Aa toxin domain II loop 1 as the binding site of Tenebrio molitor cadherin repeat CR12. Insect Biochem. Mol. 2015, 59, 50-57. [CrossRef]

36. Gómez, I.; Sánchez, J.; Muñoz-Garay, C.; Matus, V.; Gill, S.S.; Soberón, M.; Bravo, A. Bacillus thuringiensis Cry1A toxins are versatile proteins with multiple modes of action: Two distinct pre-pores are involved in toxicity. Biochem. J. 2014, 459, 383-396. [CrossRef]

37. Tabashnik, B.E.; Huang, F.; Ghimire, M.N.; Leonard, B.R.; Siegfried, B.D.; Rangasamy, M.; Yang, Y.; Wu, Y.; Gahan, L.J.; Heckel, D.G.; et al. Efficacy of genetically modified Bt toxins against insects with different genetic mechanisms of resistance. Nat. Biotechnol. 2011, 29, 1128-1131. [CrossRef]

38. Pan, Z.Z.; Xu, L.; Liu, B.; Zhang, J.; Chen, Z.; Chen, Q.X.; Zhu, Y.J. PxAPN5 serves as a functional receptor of Cry2Ab in Plutella xylostella (L.) and its binding domain analysis. Int. J. Biol. Macromol. 2017, 105, 516-521. [CrossRef]

39. Lu, K.; Gu, Y.; Liu, X.; Lin, Y.; Yu, X. Possible insecticidal mechanisms mediated by immune-response-related Cry-binding proteins in the midgut juice of Plutella xylostella and Spodoptera exigua. J. Agric. Food Chem. 2017, 65, 2048-2055. [CrossRef]

40. Danaher, M.; Howells, L.C.; Crooks, S.R.; Cerkvenik-Flajs, V.; O'Keeffe, M. Review of methodology for the determination of macrocyclic lactone residues in biological matrices. J. Chromatogr. B. 2006, 844, 175-203. [CrossRef]

41. Xu, L.; Pan, Z.Z.; Zhang, J.; Niu, L.Y.; Li, J.; Chen, Z.; Liu, B.; Zhu, Y.Z.; Chen, Q.X. Exposure of helices $\alpha 4$ and $\alpha 5$ is required for insecticidal activity of $\mathrm{Cry} 2 \mathrm{Ab}$ by promoting assembly of a prepore oligomeric structure. Cell. Microbiol. 2018, 20, e12827. [CrossRef]

42. Danishefsky, S.J.; Armistead, D.M.; Wincott, F.E.; Selnick, H.G.; Hungate, R. The total synthesis of the aglycon of avermectin A1a. J. Am. Chem. Soc. 1987, 109, 8117-8119. [CrossRef]

43. Mrozik, H.; Eskola, P.; Fisher, M.H.; Egerton, J.R.; Cifelli, S.; Ostlind, D.A. Avermectin acyl derivatives with anthelmintic activity. J. Med. Chem. 1982, 25, 658-663. [CrossRef]

44. Pan, Z.Z.; Zhu, Y.J.; Chen, Z.; Ruan, C.Q.; Xu, L.; Chen, Q.X.; Liu, B. A protein engineering of Bacillus thuringiensis $\delta$-endotoxin by conjugating with 4"-O-succinyl abamectin. Int. J. Biol. Macromol. 2013, 62, 211-216. [CrossRef]

45. Wiecikowski, A.; Santos Cabral, K.M.; Silva Almeida, M. Ligand-free method to produce the anti-angiogenic recombinant Galectin-3 carbohydrate recognition domain. Protein Express Purif. 2018, 144, 19-24. [CrossRef]

46. Du, W.; Yuan, Y.; Wang, L.; Cui, Y.; Wang, H.; Xu, H.; Liang, G. Multifunctional bioconjugate for cancer cell-targeted theranostics. Bioconj. Chem. 2015, 26, 2571-2578. [CrossRef] 
47. Shao, E.; Lin, L.; Chen, C.; Chen, H.Z.; Zhuang, H.H.; Wu, S.Q.; Sha, L.; Guan, X.; Huang, Z. Loop replacements with gut-binding peptides in Cry1Ab domain II enhanced toxicity against the brown planthopper, Nilaparvata lugens (Stål). Sci. Rep. 2016, 6, 20106. [CrossRef]

48. Li, Z.; Munro, K.A.; Narouz, M.R.; Lau, A.; Hao, H.; Crudden, C.M.; Horton, J.H. Self-assembled N-heterocyclic carbene-based carboxymethylated dextran monolayers on gold as a tunable platform for designing affinity capture biosensor surfaces. ACS Appl. Mater. Interfaces 2018, 10, 17560-17570. [CrossRef]

49. Sharma, S.; Oot, R.A.; Wilkens, S. MgATP hydrolysis destabilizes the interaction between subunit $\mathrm{H}$ and yeast V1-ATPase, highlighting H's role in V-ATPase regulation by reversible disassembly. J. Biol. Chem. 2018, 293, 10718-10730. [CrossRef]

50. Gates, Z.P.; Vinogradov, A.A.; Quartararo, A.J.; Bandyopadhyay, A.; Choo, Z.N.; Evans, E.D.; Halloran, K.H.; Mijalis, A.J.; Mong, S.K.; Simon, M.D.; et al. Xenoprotein engineering via synthetic libraries. Proc. Natl. Acad. Sci. USA 2018, 115, 5298-5306. [CrossRef]

51. Ma, D.; Wang, Z.; Merrikh, C.N.; Lang, K.S.; Lu, P.; Li, X.; Merrikh, H.; Rao, Z.; Xu, W. Crystal structure of a membrane-bound o-acyltransferase. Nature 2018, 562, 286-290. [CrossRef]

52. Callaway, H.M.; Welsch, K.; Weichert, W.; Allison, A.B.; Hafenstein, S.L.; Huang, K.; Iketani, S.; Parrish, C.R. Complex and dynamic interactions between parvovirus capsids, transferrin receptors and antibodies control cell infection and host range. J. Virol. 2018, 92, e00460-18. [CrossRef]

53. Tajne, S.; Boddupally, D.; Sadumpati, V.; Vudem, D.R.; Khareedu, V.R. Synthetic fusion-protein containing domains of Bt Cry1Ac and Allium sativum lectin (ASAL) conferred enhanced insecticidal activity against major lepidopteran pests. J. Biotechnol. 2014, 171, 71-75. [CrossRef]

54. Vilar, S.; Cozza, G.; Moro, S. Medicinal chemistry and the molecular operating environment (MOE): Application of QSAR and molecular docking to drug discovery. Curr. Top. Med. Chem. 2008, 8, 1555-1572. [CrossRef]

55. Demizu, Y.; Shibata, N.; Hattori, T.; Ohoka, N.; Motoi, H.; Misawa, T.; Shoda, T.; Naito, M.; Kurihara, M. Development of BCR-ABL degradation inducers via the conjugation of an imatinib derivative and a cIAP1 ligand. Bioorg. Med. Chem. Lett. 2016, 26, 4865-4869. [CrossRef] 